\title{
The Advertising Spending Trends: Mobile Vs Traditional Media-- An Empirical Study
}

\author{
Chiang-nan Chao ${ }^{1, *}$, Yanni Ping ${ }^{1} \&$ Yingchuan Wang ${ }^{2}$ \\ ${ }^{1}$ Tobin College of Business, St. John's University, Jamaica, New York, USA \\ ${ }^{2}$ BNP Paribas, Hong Kong \\ *Correspondence: Tobin College of Business, St. John's University, Jamaica, New York, USA
}

Received: February 27, 2019

Accepted: April 12, $2019 \quad$ Online Published: May 13, 2019

doi:10.5430/mos.v6n2p1

URL: https://doi.org/10.5430/mos.v6n2p1

\begin{abstract}
Mobile commerce has become a driving force in retail industry in the past 20 years. Since Apple introduced its first generation of iPhone in 2007, smartphone has penetrated about $70 \%$ of US population. Consequently, mobile commerce has emerged from a supplementary to electronic commerce and has become a powerhouse in retail businesses. The American adults spend more time on their smartphones, and do even more commerce on their smartphone than on their personal computers. In next few years, US mobile commerce will be a half of the total ecommerce. Marketers have spent more advertising dollars on smartphones, as they can better target smartphone users through programmatic advertising, particularly when they find the phone users are interested in particular products they browse. This study compares the advertising effectiveness on smartphone users through an empirical survey. The results suggest that smartphone advertising is an effective way to reach and influence the users. Mobile advertising will continue to work hand-in-hand with traditional media advertising. A strategic shift with more focus on mobile advertising will be more effective.
\end{abstract}

Keywords: mobile advertising, advertising effectiveness, mobile commerce, electronic commerce

\section{Introduction}

US retail mobile commerce sales increased about $23 \%$ in 2018 to $\$ 133$ billion. That translates to $27 \%$ of the total retail ecommerce sales. The bulk of US retail mcommerce growth is in line with rapid growth of smartphone sales, as US smart phone has penetrated about $72 \%$ of the population in 2018 , and the average adult daily usage of smart phone had outpaced the uses of personal computers for the first time a year earlier (Statista, 2018).

Fifth generation (5G) is being built out, while fourth-generation (4G) traffic has exceeded third-generation (3G) traffic in 2015. In 2017, the 4G connection penetrated 94\% of the North America (eMarketer, 2017a), while the mobile traffic accounted for about $9 \%$ of the total traffic. Mobile offload has exceeded cellular traffic for the first time since 2015. Fifty-one percent of total mobile data traffic was offloaded onto the fixed network through Wi-Fi or femtocell in 2015. In total, 3.9 exabytes of mobile data traffic were offloaded onto the fixed network each month (Cisco, 2018).

The rapid advertisement spending growth on smartphone raises the interests for the researchers and practitioners: what need to know about mobile advertising. This empirical study intends to focus on the mobile advertising effectiveness vs. traditional media advertising, in order to provide some insights for marketer in their strategic thinking.

\section{Review of Literature}

The global smartphone shipments has outpaced personal computers and tablets in the recent years, as the smartphones, always handy, make it easier and convenient for the users to browse for the information about products. Figure 1 presents the global smartphone shipment in the recent years and prediction for the next few years. 




Figure 1. Global Smartphone Shipment, 2013-2021, in Mil of Units

Source: Gartner

https://www.statista.com/statistics/265878/global-shipments-of-pcs-tablets-ultra-mobiles-mobile-phones/

US adults have spent more time on their smartphones than on the traditional media, and this trend will continue. Figure 2 illustrates time spent by the US adults on their smartphones.

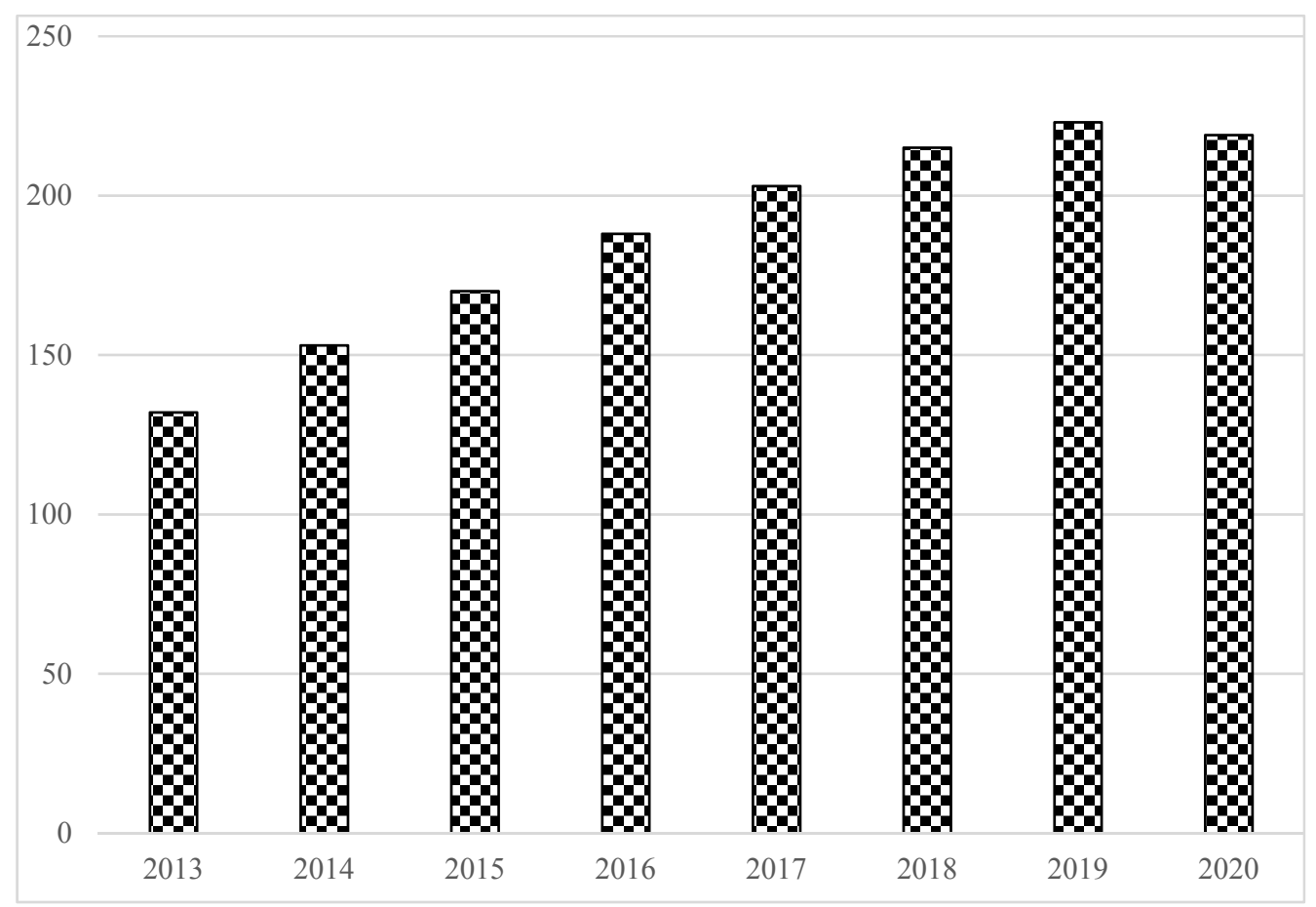

Figure 2. Time Spent on the Smartphones, USA, per Adult User per Day, in Minutes

Source: eMarketer, 2018. https://www.emarketer.com/content/mobile-soon-to-pass-tv-in-time-spent

Fulgoni and Lipsman (2016) studied future mobile commerce. They discovered that marketers who looked only at the bottom-line effects of mobile shopper activities on retailing were missing important clues about the future. 
"Mobile still is not a significant channel in driving actual purchases," observe comScore, Inc. CEO, Gian M. Fulgoni, and VP of Marketing and Insights, Andrew Lipsman. Yet, "data from Deloitte forecast that in 2016, mobile will have influenced $\$ 689$ billion in U.S. in-store sales, up from just $\$ 158$ billion in 2012 -a compound annual growth rate of 45 percent. These mobile-influenced sales figures account for in-store product purchases for which a mobile device aided in the shopping experience". Figure 3 presents the advertising spending, mobile vs. traditional media.

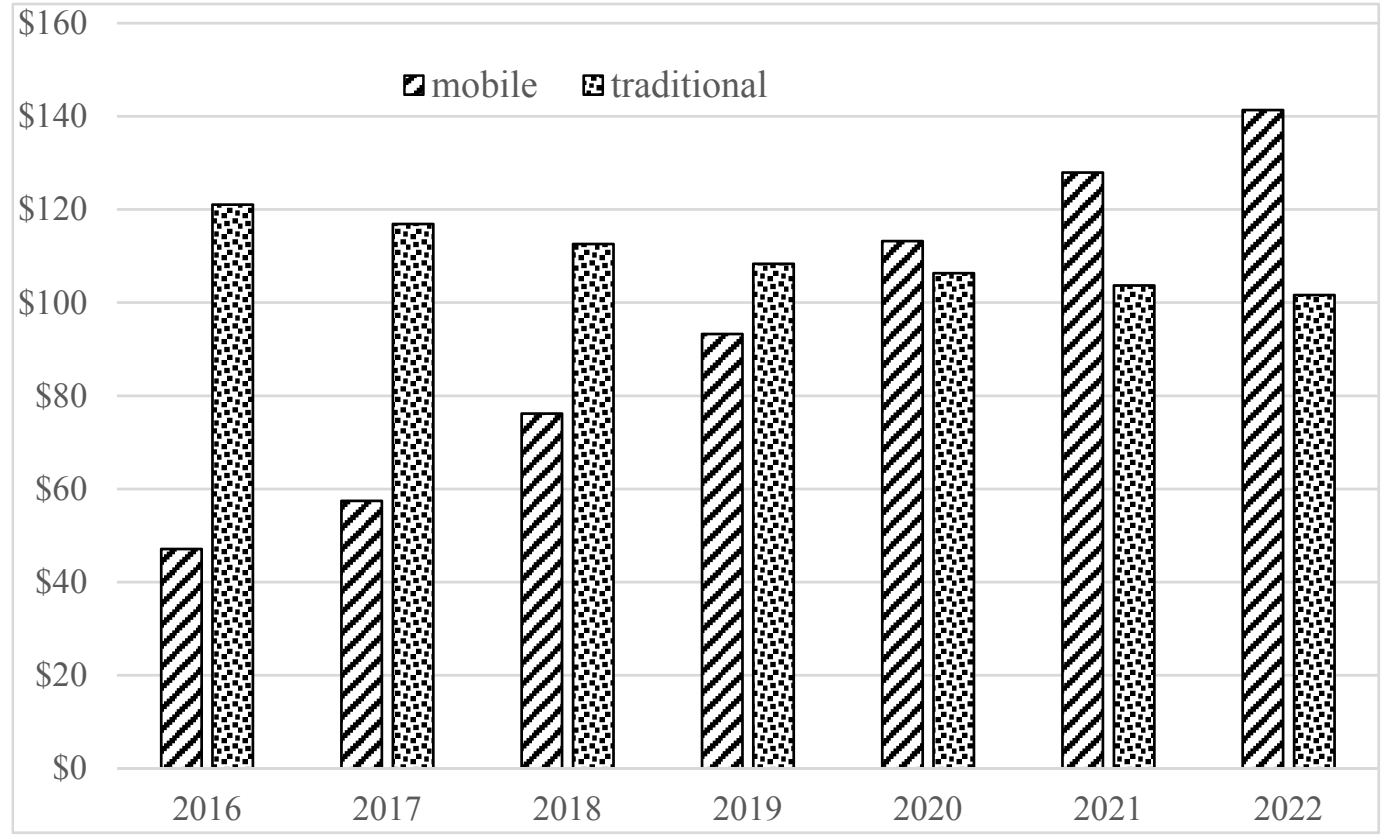

Figure 3. US Ad Spending Mobile vs. Traditional Media, in US\$ bil

Source: eMarketer, Sept. 2018.

https://www.emarketer.com/Chart/US-Total-Media-Ad-Spending-by-Media-2016-2022-billions/222668

According to a survey conducted by Clutch, a B2B research firm, almost seven in 10 mcommerce app users in the US access the apps to receive deals and offers. Nearly as many said they appreciate them for the flexibility to buy at any time. New data from The Integer Group illustrates the rapid shift of consumer behavior over the past few years. In surveys conducted in 2012 and 2016, the percentage of internet users who make purchases via mobile device rose substantially, from just a quarter in 2012 to nearly two-thirds last year (eMarketer, 2017b).

Yang and Lee (2017) focused on distinguishing mobile interactivity (m-interactivity) from interactivity via fixed broadband Internet (e-interactivity). They explored several comprehensive dimensions of interactivity, and identify four key dimensions of m-interactivity by conducting both exploratory factor analysis and confirmatory factor analysis. They established the influence of m-interactivity on the consumer response variables of enjoyment, satisfaction, and loyalty, as well as the relationships among them.

Stewart and Cunningham (2017), and Ford (2017) studied the mobile form of marketing and revealed that this platform offered consumers unique experiences and a diverse selection of content. They discovered that with so many platforms at consumers' disposal, advertisers struggle to track the usage of each platform and the response to advertising on it. Marketers aim to reach, resonate with, and evoke a reaction from the right audience at the right time, which increases the importance of multiplatform metrics. They offered further theoretical explanations and managerial implications.

Hsu and Yeh (2018) find four critical success factors that influence M-commerce adoption: perceived ease of use, perceived usefulness, value-added and service functionality. In addition, these factors were identified as the cause and effect factors. The results of this study are presented to M-commerce service providers' in facilitating the development of wireless services. Lin, et al (2017) explored the determinants of consumers' use of mobile commerce, and their act of payment. They found that security concerns and privacy concerns are the most important factors. 
Raphaeli, et al. (2017) analyzed online consumer behavior in mobile and PC devices. They investigated and compared online consumer behavior on an e-retailer website in mobile versus PC devices, through the application of a web usage mining approach on clickstream data recorded in server-side log files. Online consumer behavior is characterized through both engagement measures and the discovery of common sequences of navigation patterns, using an innovative approach that combines footstep graph visualization with sequential association rule mining. They found that sessions conducted through mobile devices are more likely to consist of task-oriented behavior whereas sessions conducted through PC devices are characterized by a more exploration-oriented browsing behavior. They also found that certain sequence rules were associated with an increased likelihood of purchase in both mobile and $\mathrm{PC}$ sessions.

Chao (2017) investigated mobile commerce, which has emerged as an important sector in retail businesses, as US smartphones have penetrated near $80 \%$ of the population in 2017 . The average adult daily usage of smart phone outpaced personal computers for the first time, and the users do more commerce on their smartphones than on their personal computers. As predicted by eMarketer US mcommerce will be a half of the total ecommerce by 2020 . As a result, marketers have spent advertisement on smartphones. The marketers realize that they can better target smartphone users through programmatic advertising, particularly when they find the phone users are interested in particular products they browse. This research, through an empirical survey, focuses on the effectiveness of mobile marketing. The research results confirm this marketing trend, and provide some useful insights for marketers in their future marketing endeavors.

The review of literature tenders a wide range of aspects for mobile commerce. While this study intends to focus only on the fundamental issues: the limited aspects of smartphone user behavior, and comparisons of computer and smartphone usages. The objective of the study intends to provide some insights to marketers that would help them better reach their customers.

\section{Methodology}

This study focuses on the advertising effectiveness on smartphone users. A survey questionnaire was designed to investigate the features that were most important for the advertisers.

\subsection{Variable Selection}

The variables that were selected are based on our literature review. Twelve research variables were identified from the review of literature and presented below. The respondents were asked to identify how frequently they were aware of the advertising messages, presented either in the mobile form or in the form of the traditional media. The respondents were asked to evaluate the frequency they would notice each of these variable messages advertised in mobile advertising and in traditional media advertising. Five point Likert scale is applied, with $5=$ always, $4=$ mostly, $3=$ frequently, $2=$ occasionally, $1=$ never.

The following variables were evaluated:

1. Product quality and features offering

2. Offering free samples

3. Offering free trials

4. Offering attractive prices

5. Offering discounts and promotion

6. Offering coupons

7. Offering rebates

8. Offering incentives to buyers in online store or retail stores

9. Offering free delivery or delivery incentives

10. Offering prizes

11. Offering sweepstakes

12. Offering sport or cultural sponsorship 


\subsection{Sampling, Hypotheses, and Tests of Hypotheses}

The targeted sample respondents were college students in a large university in the northeast of the U.S. One-page survey questionnaires were distributed online and/or delivered to the potential respondents, specifically with the aim of obtaining the opinions of the respondents who are often exposed to both traditional and mobile advertising. The null hypotheses for this study stated:

$H_{I}$ There is no significant difference in product quality and/or features offering between mobile media and traditional media advertising.

$\mathrm{H}_{2}$ There is no significant difference in offering free samples between mobile media and traditional media advertising.

$\mathrm{H}_{3}$ There is no significant difference in offering free trials between mobile media and traditional media advertising.

$\mathrm{H}_{4}$ There is no significant difference in offering attractive prices between mobile media and traditional media advertising.

$H_{5}$ There is no significant difference in offering discounts and promotion between mobile media and traditional media advertising.

$H_{6}$ There is no significant difference in offering coupons between mobile media and traditional media advertising.

$H_{7}$ There is no significant difference in offering rebates between mobile media and traditional media advertising.

$H_{8} \quad$ There is no significant difference in offering incentives to buyers in mobile media store or retail stores between mobile media and traditional media advertising.

$H_{9}$ There is no significant difference in offering free delivery or delivery incentives between mobile media and traditional media advertising.

$H_{10}$ There is no significant difference in offering prizes between mobile media and traditional media advertising.

$H_{11}$ There is no significant difference in offering sweepstakes between mobile media and traditional media advertising.

$H_{12}$ There is no significant difference in offering sport or cultural sponsorship between mobile media and traditional media advertising.

The alternative hypotheses state: there is significant relationship between the respondents' views of mobile media advertising and traditional media advertising over these selected variables.

When two samples are involved and the values for each sample are collected from the same individuals (that is, each individual gives two values: one for each of the two categories), or the samples come from matched pairs of individuals, a paired-samples $t$-Test is an appropriate statistic to use. The paired samples $t$-Test can be used to determine if two means are different from each other when the two samples that the means are based on were taken from the matched individuals or the same individuals. The paired samples $t$-Test used compared the means of two variables. This procedure allowed the computation of the difference between the two variables for each case, and tests to see if the average difference is significantly different from zero, assuming that both variables should be normally distributed. The nulls are rejected if the significance levels are less than or equal to ten percent of the criteria, in other words, ten percent of the paired sample $t$-Test two-tailed probability level signifies the differences in effectiveness between the expectations and fulfillments of these expectations (Conover, 1980; Davis \& Cosenza, 1985; Hamburg, 1977; SPSS $^{\mathrm{X}}$, 2002). So, for this research a 10\% significance level was set to reject the null hypotheses.

\section{Results}

One thousand two hundred questionnaires were distributed in a large university in the northeast of the U.S., of which three hundred ninety three were returned and usable. This represents roughly 33 percent response rate. The following table presents the background information of these respondents, including gender and income. 
Table 1. Background Information of the Respondents

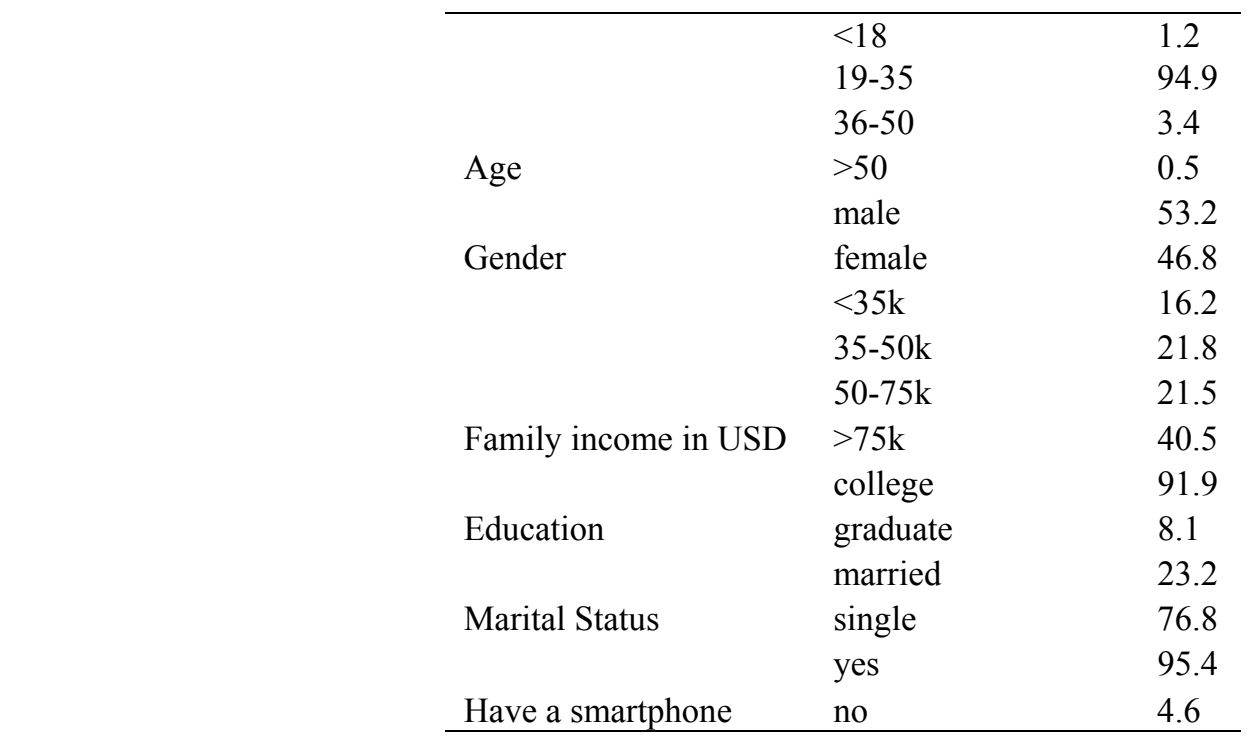

Source: Original

Overall, the means of traditional media advertising are higher than those of smartphone advertising. Table 2 shows the Paired Samples $t$-Test Results. It indicates that eight out of twelve paired variables test results show significance levels less than 5\% (highlighted in bold). Therefore, these hypotheses where there are significant differences between the respondents' views of smartphone advertising versus traditional advertising messages. The remaining four paired variables test results show significance levels more than 5\%. Therefore, these hypotheses are accepted: for these promotional elements there are no significant differences in the respondents' awareness based on smartphone advertising messages and the traditional media advertising messages.

Table 2. The Paired Samples $t$-Test Results

\begin{tabular}{lllll}
\hline Variables & Mean & $\boldsymbol{t}$ & df & Sig. (2-tailed) \\
\hline Product quality and features offering & $\mathbf{- 0 . 6 3}$ & $\mathbf{- 8 . 1 7}$ & $\mathbf{3 9 1}$ & $\mathbf{0 . 0 0}$ \\
Offering free samples & $\mathbf{- 0 . 4 8}$ & $\mathbf{- 5 . 9 8}$ & $\mathbf{3 9 2}$ & $\mathbf{0 . 0 0}$ \\
Offering free trials & $\mathbf{- 0 . 3 6}$ & $\mathbf{- 4 . 3 5}$ & $\mathbf{3 9 1}$ & $\mathbf{0 . 0 0}$ \\
Offering attractive prices & $\mathbf{- 0 . 3 6}$ & $\mathbf{- 4 . 4 3}$ & $\mathbf{3 8 8}$ & $\mathbf{0 . 0 0}$ \\
Offering discounts and promotion & $\mathbf{- 0 . 3 7}$ & $\mathbf{- 4 . 2 7}$ & $\mathbf{3 8 9}$ & $\mathbf{0 . 0 0}$ \\
Offering coupons & $\mathbf{- 0 . 4 4}$ & $\mathbf{- 5 . 3 8}$ & $\mathbf{3 9 0}$ & $\mathbf{0 . 0 0}$ \\
Offering rebates & $\mathbf{- 0 . 5 1}$ & $\mathbf{- 6 . 3 5}$ & $\mathbf{3 9 0}$ & $\mathbf{0 . 0 0}$ \\
Offering incentives to buyers in online store or retail stores & $\mathbf{- 0 . 9 8}$ & $\mathbf{- 1 1 . 8 4}$ & $\mathbf{3 8 9}$ & $\mathbf{0 . 0 0}$ \\
Offering free delivery or delivery incentives & -0.10 & -1.21 & 389 & 0.23 \\
Offering prizes & 0.05 & 0.65 & 389 & 0.52 \\
Offering sweepstakes & 0.05 & 0.62 & 390 & 0.54 \\
Offering sport or cultural sponsorship & -0.03 & -0.37 & 390 & 0.71 \\
\hline
\end{tabular}

\section{Managerial Implications and Recommendations}

The Paired Samples $t$-Test results reject eight of the twelve null hypotheses; therefore, the study concludes that there are statistically significant differences from the consumers' viewpoints between smartphone and traditional media advertising. The findings suggest that although traditional media advertising continues to hold its position, the rise of smartphone advertising prevails to be more effective. For the foreseeable future, traditional media advertising and smartphone advertising may work more effectively together for marketers to target their potential customers. 
The rejections of Product quality and features offering, Offering free samples, Offering free trials, Offering attractive prices, Offering discounts and promotion, Offering coupons, Offering rebates, Offering incentives to buyers in online store or retail stores, the respondents spend more time on their smartphones, and explore the offers of various products and/or services on their smartphone. It seems much easier for the smartphone users to access these offers. The rejections of these hypotheses offer a glimpse that more promotion can be better targeted the potential buyer groups via smartphones, rather than on the traditional media.

This study accepts four hypotheses: Offering free delivery or delivery incentives, Offering prizes, Offering sweepstakes, Offering sport or cultural sponsorship, as there are no statistically significant differences in effectiveness of the listed marketing activities between smartphone and traditional media advertising. This may suggest, from the consumers' viewpoints, it is less important for advertisers focusing on these issues when they are allocating funds to different advertising media.

The findings of this study may also suggest that traditional media advertising is giving away its importance to the mobile advertising. Credibility of this suggestion should be tested further, as this study has a preliminary nature.

Smartphone advertising has emerged as a great challenge to traditional media advertising, not only because of its many advantages, but also because it gives advertisers an additional channel to reach their potential customers and often obtain instant feedback. While researchers are inquiring the truth, practitioners are experimenting with new ways to reach their target customers; therefore the crowded advertising market is getting more crowded. The results of this research also suggest that smartphone advertising has a strong presence, and it will work hand-in-hand with traditional media advertising. A strategic balancing between the traditional media and smartphone advertising will make advertising industry more effective.

\section{Limitations and Future Research}

The literature that focuses on comparisons between traditional media and smartphone advertising is limited, and it may take a few more years before significant research publications are available. This study also finds that mobile apps are important to the users, as many of the respondents indicate that mobile advertisers' discounts can influence their purchasing decisions.

As a preliminary and exploratory research, this study has provided only limited glimpses of some fundamental aspects of smartphone advertising. Further in-depth research should delve more into the factors and elements that predict the effectiveness of traditional media versus smartphone advertising. Would consumers eventually prefer more smartphone advertising in the future? Does the younger generation differ from the older generation since younger people work more smartphone? As some of the respondents commented, they find using the smartphone enable them to handily obtain products and/or service related information. These issues should also be addressed in future research.

\section{References}

Chao, C. (2017). Emergence Impacts of Mobile Commerce: An Exploratory Study. Journal of Management and Strategy, 8(2), 63-70.

Cisco. (2018). $\quad$ VNI. $\quad$ Retrieved from https://www.cisco.com/c/en/us/solutions/collateral/service-provider/visual-networking-index-vni/white-paper-c 11-741490.html

Conover, W. J. (1980). Practical Nonparametric Statistics (2nd ed.). New York: John Wiley \& Sons, pp. 213-337 \& 344-384.

Davis, D., \& Cosenza R. M. (1985). Business Research for Decision Making. Boston: Kent Publishing.

eMarketer (2017a). 4G LTE Penetration Rate Higher in North America than Any Other Region. Retrieved from https://www.emarketer.com/content/4g-lte-has-a-higher-penetration-rate-in-north-america-than-any-other-part-o f-the-world

eMarketer (2017b). Mobile to Account for More than Half of Digital Ad Spending in 2015. Retrieved from http://www.emarketer.com/Article/Mobile-Account-More-than-Half-of-Digital-Ad-Spending-2015/1012930

eMarketer, (2018). Retrieved from https://www.emarketer.com/content/mobile-soon-to-pass-tv-in-time-spent 
Fulgoni, G. M., \& Lipsman, A. (2016). The Future of Retail Is Mobile. Journal of Advertising Research, June, 56(4), 346-351. https://doi.org/10.2501/JAR-2016-041

Hamburg, M. (1977). Statistical Analysis for Decision Making. San Diego: Harcourt.

IBM SPSS Exact Tests, SPSS Inc. (2010).

Hsu, C. W., \& Yeh, C. C. (2018). Understanding the critical factors for successful M-commerce adoption. International Journal of Mobile Communications, 16(1), 50-62.

Lin, W. R., Wang, Y. H., \& Shih, K. H. (2017). Understanding consumer adoption of mobile commerce and payment behavior: an empirical analysis. International Journal of Mobile Communications, 15(6), 628-654. https://doi.org/10.1504/IJMC.2017.10005646

Raphaeli, O., Goldstein, A., \& Fink, L. (2017). Analyzing online consumer behavior in mobile and PC devices: A novel web usage mining approach. Electronic Commerce Research and Applications, 26(November-December), 1-12. https://doi.org/10.1016/j.elerap.2017.09.003

Statista, (2018). Retrieved from https://www.statista.com/statistics/201182/forecast-of-smartphone-users-in-the-us/

Stewart, K., \& Cunningham, I. (2017). Examining Consumers' Multiplatform Usage and Its Contribution to Their Trust in Advertising--The Impact of the Device on Platform-Use Frequency and Trust in Advertising across Platforms. Journal of Advertising Research, 57(3). https://doi.org/10.2501/JAR-2017-003

Yang, S., \& Lee, Y. J. (2017). The Dimensions of M-Interactivity and Their Impacts in the Mobile Commerce Contex. International Journal of Electronic Commerce, 21(4), 548-571. 